\title{
Erratum to: Lignocellulosic Biomass for Energy, Biofuels, Biomaterials, and Chemicals
}

\author{
Abla Alzagameem, Basma El Khaldi-Hansen, Birgit Kamm, \\ and Margit Schulze
}

\section{Erratum to}

\section{Chapter 5 in: S. Vaz Jr. (ed.), Biomass and Green Chemistry, https://doi.org/10.1007/978-3-319-66736-2_5}

The original version of this chapter was published without printing the 2 nd affiliation for one of the chapter authors - Abla Alzagameem. The correct affiliation for Abla Alzagameem should be:

1 Faculty of Environment and Natural Sciences, Brandenburg University of Technology BTU Cottbus-Senftenberg, Cottbus, Germany

2 Department of Natural Sciences, Bonn-Rhein-Sieg University of Applied Sciences, Rheinbach, Germany

The original version of this chapter was inadvertently published without printing Acknowledgements. The acknowledgement section is added in the current version of this chapter as below:

Acknowledgements Financial support (scholarship) was given to Abla Alzagameem by the Avempace-II Erasmus-Mundus Programme and the Graduate Institute of the Bonn-Rhein-Sieg University of Applied Sciences.

The updated online version of the chapter can be found at https://doi.org/10.1007/978-3-319-66736-2_5 